\title{
ENRIQUE DE VILLENA Y CURIAL E GÜELFA
}

\author{
Abel SOLER \\ abel_soler@yahoo.es \\ Universitat de València
}

Enrich o Enrique de Villena (1384-1434) fue un noble de sangre real, pariente a partes iguales de los Trastámara reyes de Aragón y Castilla, inusualmente interesado por las letras. Su relación con la corte valenciana de Alfonso V el Magnánimo (1416-1420, 14241430) podría explicar la influencia que ejercieron sus obras sobre el anónimo autor de la novela caballeresca Curial e Güelfa (NápolesMilán?, $c a$. 1445-1448) $)^{1}$, redactada en un catalán marcado por preferencias léxicas valencianas ${ }^{2}$. El presente estudio pretende evidenciar puntos de contacto entre Villena y el autor del Curial, e incitar a los estudiosos de la obra de don Enrique y de las letras castellanas de su tiempo a explorar el relato caballeresco catalán con este mismo propósito.

\section{Los DOTZE TREBALLS D 'HèrCULES (VALENCIA, 1417) Y el CURIAL}

En 1428, hallándose eventualmente Enrique de Villena en la corte y Palacio del Real de Valencia (capital por aquel entonces de la Corona de Aragón), decidió dedicar al rey Juan de Navarra, allí residente, su traducción glosada de la Eneida «en la materna lengua castellana» ${ }^{3}$ que ambos compartían; aunque don Enrich se había criado en lengua catalana en Gandía, en la corte ducal de su abuelo, Alfons d'Aragó el Vell ${ }^{4}$. Fue probablemente en Valencia donde Enrique engendró a

${ }^{1}$ El contexto, la datación y las fuentes literarias del Curial son analizados en profundidad en Abel Soler, La cort napolitana d'Alfons el Magnànim: el context de "Curial e Güelfa», Tesis doctoral dirigida por Antoni Ferrando, Valencia, Departament de Filologia Catalana-Facultat de Filologia, Traducció i Comunicació-Universitat de València, 2016, 5112 pp. Publicada con el mismo título, Valencia-Barcelona, Universitat de València-Institut d'Estudis Catalans-Institució Alfons el Magnànim, 2017, 3 vols., 4754 pp.

${ }^{2}$ Véase, entre otros, Joan Veny, «Valencianitat del Curial», en A. Ferrando (ed.), Estudis lingüistics $i$ culturals sobre "Curial e Güelfa», novel-la cavalleresca anònima del segle XV en llengua catalana, Ámsterdam, John Benjamins, 2012, pp. 1089-1106.

${ }^{3}$ Enrique de Villena, Traducción y glosas de la «Eneida», en Obras completas, P. M. Cátedra (ed.), Madrid, Turner, 1994-2000, vols. II-III (2000), vol. II, p. 5.

${ }^{4}$ Prueba de ello son, aparte de sus obras y sus cartas en catalán, los catalanismos léxicos y sintácticos que afectan a su mucho más extensa producción en castellano. Vid. José A. Pascual, La traducción de la «Divina comedia» atribuida a D. Enrique de Aragón. Estudio y edición del «Infierno», Salamanca, Universidad de Salamanca, 1974, p. 206; Pedro M. Cátedra, «Sobre la obra catalana de Enrique de Villena», en L. López y A. Redondo (eds.), Homenaje a Eugenio Asensio, Madrid, Gredos, 1988, pp. 127-140. El catalán le sirvió de lengua puente, además, 
su hija bastarda, la futura sor Isabel de Villena, destinada a ser una de las grandes escritoras del siglo de oro valenciano. Aunque por sus estrechos vínculos con la nobleza y con la corte de Castilla prefiriese escribir en castellano, el noble optó por redactar en catalán Los dotze treballs d'Hèrcules (Valencia, 1417) a petición del señor de Albaida, un Pardo de la Casta. El mismo Enrique tradujo dicha obra al castellano pocos años después ${ }^{5}$. No es descartable, pues, que en la década de 1420 Villena pudiese haber convivido en la corte de Valencia con el que más adelante sería lector atento de su obra y autor del Curial. Recordemos que, en la Valencia de 1424, como iniciativa excepcional en la Península Ibérica, los jurats contrataban a «poetas» italianos para que impartiesen lecciones sobre la Consolación de Boecio, la Eneida de Virgilio y otros clásicos en la Casa de la Ciudad 6 .

Villena tuvo acceso a enciclopedias y otras obras del Trecento y fue cliente especial de los cartolai de la Florencia de Leonardo Bruni. Sin embargo, no profundizó para nada en el pensamiento humanista. Su espíritu era todavía el de un autor medieval ${ }^{7}$. Con todo, escribió animado por el acicate proselitista de iniciar en la "sçiençia» a nobles cortesanos interesados como él en astrología, mitografía y literatura clásicas, entre otros conocimientos. Se dirigió por ello a los «romançistas»: aquellos «que no sabrían latýn», es cierto, pero que anhelaban acceder -mediante traducciones y glosas- a los secreta subyacentes bajo la «mar de las ystorias» antiguas ${ }^{8}$. Su falta de rigor y sus conocidas extravagancias dificultaron el pleno éxito del proyecto, aunque consiguió despertar en autores como Santillana - «familiar», siendo joven, del rey de Aragón- $-^{9}$ o el anónimo del Curial un vivo interés por las novedades que venían de Italia.

para traducir al castellano obras italianas, según Joaquín Rubio Tovar, «Traductores y traducciones en la Biblioteca del Marqués de Santillana», en J. S. Paredes (coord.), Medioevo y literatura. Actas del $V$ Congreso de la Asociación Hispánica de Literatura Medieval (Granada, 1993), Granada, Universidad de Granada, 1995, vol. IV, pp. 243-252 (p. 247).

${ }^{5}$ Emilio Ridruejo, «Tres catalanismos (y aragonesismos) sintácticos en Los doze trabajos de Hércules del marqués de Villena», Archivo de filología aragonesa, 34-35, 1984, pp. 273290 (p. 274, n. 7). El único ejemplar que se conserva de la versión catalana -inédito, excepto el proemio- se corresponde con una impresión de 54 folios realizada en Valencia por Cofman en 1530 .

${ }^{6}$ Lluís Nicolau D’Olwer, «La Eneida a Catalunya», Ofrena, 7 (1918), pp. 9-10.

${ }^{7}$ Ottavio Di Camillo, El humanismo castellano del siglo $\mathrm{x}$, Valencia, Fernando Torres, 1976, p. 114-115.

${ }^{8}$ Sobre el pensamiento literario de Villena, sometido a inercias medievales, y su contexto cultural, vid. Guillermo Serés, «La ficción y la "verdad del entendimiento": algunas consideraciones de poètica medieval», Revista de poética medieval, 4 (2000), pp. 153-186; Pedro M. Cátedra, «El sentido involucrado y la poesía del siglo xv. Lecturas virgilianas de Santillana, con Villena», en A. Menéndez y V. Roncero (eds.), «Nunca fue pena mayor». Estudios de literatura española en homenaje a Brian Dutton, Cuenca, Universidad de Castilla-La Mancha, 1996, pp. 149-161.

${ }^{9}$ Miguel A. Pérez Priego, «El Marqués de Santillana y la Corona de Aragón en el marco del humanismo peninsular", Revista de lenguas y literaturas catalana, gallega y vasca, 9 (2003), pp. 29-36 (p. 30) 
Constata Lola Badia que el autor de la novela catalana es alguien que «comparteix tot de dèries» con Villena y Santillana ${ }^{10}$. Añade Stefano Cingolani que «non è da scludere che conoscesse» o que hubiese leído Los dotze treballs d'Hèrcules o la Eneida en versión de Villena ${ }^{11}$. En efecto, parece que conocía bien ambas obras. Si Joanot Martorell, el autor del Tirant -la otra gran narración caballeresca de las letras catalanas-, plagió el proemio a Los dotze treballs de Villena para dotar de prólogo su obra ${ }^{12}$, el redactor del Curial declaraba: «oyts he moltes vegades, e encara legits, Los dotze treballs d'aquell [Hércules] qui en son temps fonch pus fort dels cavallers, ço és, lo fill de Júpiter e Almena, qui matà jagants, leons, serps e destruí los mònstruos seguint-los per moltes parts del món» $\left(C e G\right.$ III.0) ${ }^{13}$. Se refiere, sin duda, a la obra de Villena ${ }^{14}$, que todos en la corte tendrían en mente; que todos habrían oído recitar, como él, «moltes vegades». En el Curial, además, se dice que una culta doncella de Túnez «legia l'Eneydos de Virgili, lo qual ella en lengua materna tenia ben glosat e moralizat, car son pare lo havia haüt del rey» (CeG III.43). Los oyentes de la novela, obviamente, pensarían per speculum en la Eneida bien glosada y moralizada en romance por Enrique de Villena ${ }^{15}$; una obra, sin duda, digna de estar en posesión de un rey: de Navarra, de Nápoles... o de Túnez, siendo accesible a su círculo de cortesanos.

A parte del interés más o menos implícito del escritor del Curial por el legado literario de Villena, Xavier Gómez puso en evidencia la «afinitat de fonts» entre ambos autores ${ }^{16}$ y la consulta por los dos de fuentes de erudición italianas. Ninguno de ellos responde al

${ }^{10}$ Lola Badia, «Nota-ressenya a Anton Espadaler, Una reina per a Curial, Barcelona, Quaderns Crema, 1984», Els Marges, 34 (1986), pp. 117-120 (p. 120). Vid. etiam Lola Badia, «La segona visió mitològica de Curial i notes per a una interpretació de l'anònim català del segle XV», en V. Beltran (ed.), Actas del I Congreso de la Asociación Hispánica de Literatura Medieval (Santiago de Compostela, 2 al 6 de diciembre de 1985), Santiago de Compostela, 1988, pp. 157-176; reed. en Estudis de Llengua i Literatura Catalanes, 14 (1987), pp. 265-292 (p. 268).

${ }^{11}$ Stefano M. Cingolani, «Finzione della realtà e realtà della finzione. Considerazioni sui modelli culturali del Curial e Güelfa», en L. Badia y A. Soler (eds.), Intel-lectuals i escriptors de la baixa edat mitjana, Barcelona, Curial-Publicacions de l'Abadia de Montserrat, 1994, pp. 124-159 (pp. 132 y 144).

${ }^{12}$ Se hallarán ambos textos, comparados, en Martí de Riquer, Aproximació al «Tirant lo Blanc», Barcelona, Quaderns Crema, 1990, pp. 275-278.

${ }^{13}$ Se cita a partir de la edición de Antoni Ferrando, Curial e Güelfa, Toulouse, Anacharsis, 2007, por haberse respetado en ella, con fidelidad paleográfica, el texto del manuscrito. Se reseña el título en forma abreviada $(C e G)$, seguido del libro en numeración romana (I, II o III) y del capítulo en cifras arábigas.

${ }^{14}$ Como dedujo, lógicamente, Xavier Gómez, «Curial e Güelfa», petges mitològiques, Memoria de licenciatura, Valencia, Departament de Llengua i Literatura Llatines-Universitat de València, 1986, pp. 90-91, n. 51; Idem, «Curial e Güelfa, petges mitològiques», Caplletra, 3 (1988), pp. 41-63 (p. 51, n. 48). Alteramos por ello el criterio de edición de Ferrando (2007), para plasmar en cursiva Los treballs, por entenderlo como la remisión al título de una obra literaria familiar para los «oyentes».

${ }^{15}$ Lola Badia y Jaume Torró, «Curial e Güelfa», en A. Broch (dir.), Història de la literatura catalana, vol. III. Literatura medieval (III). Segle XV (L. Badia, dir.), Barcelona, Enciclopèdia Catalana-Barcino-Ajuntament de Barcelona, 2015, pp. 55-106 (p. 90).

${ }^{16}$ Gómez, «Curial e Güelfa», petges, op. cit., p. 77, 88-90 y n. 50. 
perfil intelectual de «home de sciència», de 'profesional' de la letra, por usar una expresión recurrente en Curial e Güelfa. Debieron ser ambos literatos dos cortesanos de aquellos que se autodenominaban «scientífichs»: estudiosos más o menos diletantes y autodidactas, como lo podía ser asimismo -en el universo de ficción del libro catalán- el protagonista italiano del relato caballeresco. Enrique de Villena y el autor del Curial se complacieron en exhibir una erudición de segunda mano ${ }^{17}$, y parece que buscaron y hallaron fuentes de inspiración en autores italianos. El primero se interesó por obras que «non eran falladas en Castilla, e trájolas el dicho don Enrique, que las fizo venir de Florencia, onde se falla abundancia destas obras poéthicas» ${ }^{18}$. A través de aquellas enciclopedias itálicas, o de commenti de la Comedia (el autor del Curial recurrió a Benvenuto da Imola y Pietro Alighieri ${ }^{19}$ ), se podía acceder a la «ciencia», es decir, a las lecciones filosófico-morales de las fábulas greco-latinas, semiocultas bajo hermosos velos o integumentos retóricos: «E, quant a l'integument d'aquesta faula, diu Fulgenci que nou Muses són dites nou consonàncies de la veu humana...» (CeG III.0).

Sin el apoyo de los exegetas italianos, o de sus hábiles plagiadores en romances ibéricos, los caballeros aspirantes a devenir sujetos «sçientíficos» (como el mismo caballero Curial, «qui era home scientífich, e qui nulls temps lexava l'estudi», $C e G$ III.24) difícilmente hubiesen podido «entender los integumentos poéthicos» ${ }^{20} \mathrm{ni}$ desentrañar sus codificadas y prácticas «verdades». Requerían para ello de «prohemios declarativos» y exposiciones ad hoc, que les permitiesen destejer la «textual texedura»: disponer de «la expusiçión alegórica» de los mitos clásicos «e luego la verdat de aquella historia segunt realmente contesçió», así como «la aplicación moral a los estados del mundo» de las enseñanzas que estos mitos ofrecían ${ }^{21}$. Según Villena, la verdad de los historiadores la revestían los vates con alegorías o ficciones poéticas, bajo cuyo integumento yacían moralidades («doctrina latente») aplicables a la «vida çevil $»^{22}$ : «expresiones $[\ldots]$ subtintellectas, siquiere implícitas o escuro puestas», que él prometía poner a disposición, ya no del sabio o del letrado

${ }^{17}$ Para el caso de Villena, véase, por ejemplo, Paolo Cherchi, «Los Doce Trabajos de Hércules de Villena y la Fiorita de Guido da Pisa», Revista de filología española, LXXXII/3-4 (2002), pp. 381-396.

${ }^{18}$ Jeremy N. H. Lawrance, «The Spread of Lay Literacy in Late Medieval Castille», Bulletin of Hispanic Studies, 62 (1985), pp. 79-94 (p. 92, n. 20). Vid. etiam Santiago Aguadé Nieto, Libro y cultura italianos en la Corona de Castilla durante la Edad Media, Alcalá de Henares, Universidad de Alcalá, 1992, pp. 303-304.

${ }_{19}$ Juan Francisco Mesa Sanz, «Las fuentes del latín del Curial e Güelfa», en A. Ferrando (ed.), Estudis lingüistics, op. cit., vol. I, pp. 387-428.

${ }^{20}$ Villena, Traducción y glosas, op. cit., vol. II, p. 13 (glosa 14).

${ }^{21}$ Enrique de Villena, Los doce trabajos de Hércules, en Obras completas, Pedro M. Cátedra (ed.), Madrid, Turner, 1994-2000, vol. I (1994), pp. 7-8.

${ }^{22}$ Nótese, en este concepto de la vita civile, la influencia del vocabulario del primer humanismo italiano y, más concretamente, del umanesimo civile florentino. 
de oficio, sino del «symple leedor» cortesano y lego ${ }^{23}$. La ciencia, así entendida por Villena, proporcionaba al noble «curialidat» y lo rescataba de una indeseable rusticidad ${ }^{24}$. Su Hércules moralizado era el paradigma alegorizado de «las devotas e sçientes personas, que han mayor fuerça por virtud de la sçiencia e alteza de entendimiento, contemplativamente e especulativamente, buscando secretos e verdades a esto pertenesçientes $)^{25}$.

Las alegorías mitológicas ofrecían «un camino de perfección y transformación» a todo caballero lector ${ }^{26}$. No es extraño así que el Hércules de Villena reaparezca en un punto crucial del proceso formativo y regenerador de Curial para ayudarle a deplorar el vicio y a retomar lasenda de la virtud. Puesto que «así como Hércules domó las fieras e los tiranos [...], así deven los que al çielo venir quieren primero domar los viçios antes que se atrevan a coger los sagrados ramos de las eroicas virtudes» ${ }^{27}$. La lección moral del Curial parte de esta vieja dicotomía medieval (vicio vs. virtud, salvación $v s$. condenación del alma), pero reelaborada ya sobre unos cimientos ideológicos de signo humanístico e itálico: los libros de ciencias liberales y de filosofía moral, para profundizar en la virtud, y la obtención de una gloria terrenal y mundana, de contornos neoplatónicos, inspirada en la promesa de clásicos greco-latinos como La república y el Banquete de Platón, o el Somnium Scipionis comentado por Macrobio ${ }^{28}$.

Por lo que parece, algunos neologismos y frases de Villena resuenan reiteradamente en Curial e Güelfa. Por ejemplo: «la brevidat del temps no consentia que millor se fes» ( $C e G$ II.40); «molts imitadors e servidors en multitut copiosa, los quals, per gràcia de brevidat, lexaré de nomenar» ( $\mathrm{Ce} G$ III.79); «No curaré de nomenar la manera de les viandes [...], e leix-ho per gràcia de brevidat» $(C e G \text { III.103 })^{29}$. Brevidat es un cultismo latino documentado en el castellano del siglo

${ }^{23}$ Citado por Peter Russell, Traducciones y traductores en la Península Ibérica (14001500), Bellaterra, Universitat Autònoma de Barcelona, 1985, pp. 45-50. Vid. etiam Lara Vilà, «Fama y verdad en la épica quinientista española. El virgilianismo político y la tradición castellana del siglo Xv», Studia aurea, 4 (2010), pp. 1-35 (p. 15 y ss.); Serés, «La ficción y la "verdad"», art. cit., p. 174.

${ }^{24}$ José Antonio Maravall, «La "cortesía” como saber en la Edad Media», en Estudios de historia del pensamiento español, Madrid, Cultura Hispánica, 1983-1984 (3ª ed.), vol. I, pp. 254-267.

${ }^{25}$ Villena, Los doce trabajos, op. cit. (ed. Cátedra, 1994), pp. 99-100.

${ }^{26}$ Juan Miguel Valero Moreno, «Antecedentes y encrucijadas de la vida activa y contemplativa en la Castilla del Cuatrocientos», eHumanista, 29 (2015), pp. 32-71 (pp. 49-50).

${ }^{27}$ Villena, Los doce trabajos, op. cit. (ed. Cátedra, 1994), pp. 101-102, apud Valero, art. cit., p. 50.

${ }^{28}$ Sobre las fuentes que conectan ideológicamente y «estéticamente» el Curial com el neoplatonismo italiano del primer Quattrocento, incluido el redescubrimiento del Mito de Er (La república), vid. Abel Soler, «La Làquesis de Plató i la Làquesis del Curial», en «Avatares y perspectivas del medievalismo ibérico». VII Congreso Internacional de la Asociación Hispánica de Literatura Medieval (Roma, 26-30 de septiembre de 2017. Sapienza, Università di Roma), San Millán de La Cogolla, Cilengua, 2019, en prensa.

${ }^{29}$ La cursiva de estas citas y de las que vienen a continuación es nuestra. 
XIV, que el anónimo incorpora al Curial recordando tal vez el estilo de los proemios de Villena: «E ya sea aquí no estén deduzidos espeçificamente cada uno de los nombrados estados [...], sinon implíçitamente e sumaria, por graçia de brevedat» (prólogo a Los doce trabajos, versión castellana, 1421) $)^{30}$, o «puse fin a dezir en esta materia por graçia de brevidat, de que se pagan oy los modernos» (proemio del Arte cisoria, 1423) ${ }^{31}$.

Por otro lado, ya en Los dotze treballs (1417), Villena justificaba una distinción entre verdad histórica y poética ficción (los «ystorials» que escriben relatos verídicos y los «poetes, qui n'an guarnit ses fictions $\left.\rangle^{32}\right)$ que reaparece tal cual en el Curial. Aquí, «Dites, gran historial» ( $C e G$ III.26), enunció la «veritat del fet» ( $C e G$ III.34), en su ordo naturalis, sobre la guerra de Troya, un asunto debatido entre caballeros y humanistas en la corte napolitana (si se atiende al testimonio de Lorenzo Valla ${ }^{33}$ ). Sin embargo, los poetas no fingen «contra veritat»-como denuncia un satírico Apolo-, sino que saben revestir de bellas expresiones esta verdad, merced a la ciencia de Baco y a la sapiencia de Apolo (el anónimo bebe aquí de Da Imola, cuando este remite a la teología solar de Macrobio). Y lo hacen con un «sublime e maravellós estil» ( $\mathrm{Ce} G$ III.0), capaz de fascinar durante siglos a «los hòmens de sciència» ( $C e G$ III.34), que equivalen a los «omnes de sçiencia» de Los doce trabajos, pero en su renovada versión italiana: los humanistas. El autor del Curial se sitúa en un plano similar al de Villena: el de aquel que trata de acercar la virtud que transmiten los clásicos a los nobles letraheridos «usando del común fablar e fuyendo [...] de los intricados e menos entendidos por legos vocablos $\rangle^{34}$. Se excusa del mismo modo por su afán de hacer accesible la ciencia a los no letrados: «ab humil e baix parlament proceyré, axí com sabré, a aquest tercer e derrer libre, lo qual és algun poquet pus intricat que $\cdot$ ls altres primers» $(C e G$ III.0).

En Castilla, Rodrigo Alonso de Pimentel, II conde de Benavente (1420-1440), participó a su modo del afán autodidacta y bibliófilo de Villena: leía, escribía y se autotitulaba «noble e çientífico cavallero»

${ }^{30}$ Enrique de Villena, Los Doce Trabajos de Hércules (Zamora, por Antón de Centenera, 1483), ed. de P. M. Cátedra y P. Cherchi, Santander, Universidad de Cantabria, 2007, p. 20.

${ }^{31}$ Enrique de Villena, Arte cisoria; the text and concordance of Escorial manuscript f.iv.1, ed. de J. O’Neill, Madison, Hispanic Seminary of Medieval Studies («Spanish series», 37), 1987.

${ }^{32}$ Dedicatoria transcrita en Villena, Los Doce Trabajos..., op. cit. (ed. Cátedra-Cherchi, 2007), p. 111.

${ }_{33}$ Vid. Lorenzo Valla, Historia de Fernando de Aragón [1445-1446], S. López Moreda (trad.), Valencia, Anubar, 2002, pp. 209-210.

${ }^{34}$ Villena, Los Doce Trabajos, op. cit. (ed. Cátedra, 1994), p. 13. El adjetivo intricado se conocía y se usaba en ámbito cortés castellano, en el mismo sentido en que lo utilizaron Villena y el autor del Curial. Por ejemplo, en la reseña que hizo Juan Alfonso de Baena del poeta Gonzalo Martínez de Medina (Sevilla, $c$. 1380-1434): «Fue omne muy sotil e intricado en muchas cosas, de buscador de sotiles invenciones», en Juan Alfonso de Baena, El Cancionero de Juan Alfonso de Baena (siglo xv), Eugenio de Ochoa (ed.), Madrid, La Publicidad, 1851, p. 370. 
$(1439)^{35}$. De Santillana, Hernando del Pulgar destacó que «tenía siempre en su casa doctores e maestros con quien platicava en las ciencias e leturas que estudiava ${ }^{36}$. El noble científico, convenía que fuese amigo y mecenas de hombres de ciencia. Sabiéndose incapazde alcanzar por sí mismo un saber elevado, que se rodease al menos de sabios. Y «si careçemos de las formas [de conocimientos de latín y retórica], seamos contentos con las materias». Así justificó su curiosidad intelectual Santillana ante su hijo Pedro González cuando le animó a traducir la Ilíada del latín al castellano ${ }^{37}$. En la ficción curialesca, todo un rey de Francia dirá del modélico caballero italiano: «[Curial] és molt abte e virtuós, savi e de gran e notable consell, però no me'n maravell, car entre los grans philòsofs, poetes e oradors veig que és tengut en gran stima» ( $C e G$ II.116). Como Santillana, Curial nunca será un gran filósofo o poeta, pero se ayudará de ellos para elevarse en virtud moral e intelectual -mediante las letras- por encima de otros caballeros, digamos que menos curiales. El mismo autor del Curial debió de rodearse también de poetas y oradores - preceptores áulicos-para aprender de ellos y lucir lo aprendido en su novela ${ }^{38}$. Se presenta como alguien que, al igual que Santillana, se siente obligado a reconocer sus limitaciones: «Callem, donchs, los qui sabem poch, davant aquells qui saben molt» ( $C e G$ III.0). Sin embargo, conoce y propaga el ideal humanístico de los «poetes e oradors» de Italia, que invitaban a los cortesanos a ser «cavallers scientífichs» y virtuosos mediante la «vigília del studi» (< studia humanitatis): el estudio de los clásicos, de las obras «de reverenda letradura», tan veneradas por los «hòmens de molta sciència». La genealogía de suconcepto de vir scientificus se remonta al De laboribus Herculis (1406) de Coluccio Salutati, donde el héroe mitológico se convertirá en un ídolo para todo aquel que se esfuerce en el estudio y que tenga por horizonte una vida virtuosa, cimentada sobre el saber ${ }^{39}$.

En Salutati (1. II, cap. 11) se nos habla de un «Hercules, id est vir scientificus sive philosophus» para explicar que, «cum obedientia

${ }^{35}$ Citado en Pedro de Chinchilla, Libro de la Historia Troyana [1443], M. ${ }^{\text {a }}$ Dolores Peláez (ed.), Madrid, Complutense, 1999, p. 66, n. 28. Vid. etiam Isabel Beceiro Pita, «Los libros que pertenecieron a los condes de Benavente entre 1434 y 1530», Hispania. Revista española de historia, XLIII/154 (1983), pp. 237-280 (p. 241). Pimentel poseía, entre otras obras, un ejemplar de las glosas a la Eneida de Villena (ibidem, p. 272, núm. 49 del inventario), de donde extrajo la idea y el concepto de caballero científico.

${ }^{36}$ Fernando del Pulgar, Claros varones de Castilla, Robert B. Tate (ed.), Oxford, Oxford University Press, 1971, p. 24, apud Rubio, «Traductores y traducciones...», art. cit., pp. 244-245.

${ }^{37}$ Marqués de Santillana [Íñigo López de Mendoza], Obras completas, Ángel Gómez Moreno y Maxim P. A. M. Kerkhof (eds.), Barcelona, Planeta, 1988, pp. 455-457.

${ }^{38}$ En este sentido, el espíritu de la obra conecta muy bien con la vida y vivencias de Enyego d'Àvalos, gran camarlengo de Alfonso el Magnánimo, a quien se puede atribuir la autoría de la obra, sin alternativa a la vista y según lo que proponemos en Abel Soler, «Enyego d'Àvalos, autor de Curial e Güelfa?», Estudis Romànics, 39 (2017), pp. 137-165.

${ }^{39}$ Carla Maria Monti, «De laboribus Herculis: l'opus ingens di una vita», en T. De Robertis et al. (eds.), Coluccio Salutati e l'invenzione dell'Umanesimo, Florencia, Mandragora 2009, pp. 117-122. 
rationi, vir proficit et in scientie perfectionem evadit». Por ello, cuando el Curial del relato caballeresco se sumerja en el vicio y la depravación, será rescatado por las Artes Liberales y Baco/Líber, dios tutelar de dichas artes y de la filosofía moral, según los trecentistas italianos consultados por el escritor. Flanquea a Baco el mismo «Hèrcules, fill de Júpiter e de Almena, lo qual mentre visqué fonch lo pus fort e pus savi del món» (CeG III.79). En Los doce trabajos de Villena, la victoria de Hércules sobre el jabalí de Erimanto representa el abatimiento interior del «puerco» que todo humano trae dentro y que «se da a deleytes [...], cegándose en las sensuales cosas». La bestia «es el cuerpo que el hombre cría estando desierto de virtudes». Perseverando en la virtud y en el estudio se recupera «la perdida gracia», de acuerdo con una interpretación compatible con la doctrina cristiana $^{40}$, que en el Curial deviene ideal humanístico, puesto que no es la gracia de Dios la que rescata al héroe caído, sino los libros: «Curial, despertant-se [...], lo jorn següent féu cercar libres en totes les facultats, e tornà al studi» (ibidem). La lección moral del autor de la novela, a pesar del cambio de enfoque (paganitzante; la súbita aparición de san Gregorio en el sueño redentor de Curial es una provocación satírica), lo delata como un discípulo -en cierto modo- de quien, en Los dotze treballs, declaraba: «Esto fue escripto a perpetual memoria del dicho Ércules por los estoriales, a fin que los cavalleros non menospreçiasen darse a aprender a las çiençias, segunt aquéste fizo» ${ }^{41}$.

Adelantándose, pues, a las bellas artes del Renacimiento, Villena quiso proyectar en ámbito hispánico la imagen de un Hércules que fuese «espejo actual a los gloriosos cavalleros en armada cavallería $\rangle^{42}$. Pero no únicamente por sus proezas memorables en las armas, sino también -como lo expone Jeremy Lawrance- «rather like Curial, a considerable natural philosopher and scholar as well $»^{43}$. La reivindicación del vástago de Júpiter como la figura tutelar del moderno caballero de armas y letras conecta -mucho más en el Curial

${ }^{40}$ Enrique de Villena, Los doze trabajos de Hércules [Burgos, Juan de Burgos, 1499], Eva Soler Sasera (ed.), Valencia, Universitat de València, [En línea] Enlace: <parnaseo.uv.es/ Lemir/textos/Hercules/Villena_Hercules.htm> [Consulta: 6/12/2016].

${ }^{41}$ Villena, Los doce trabajos, op. cit. (ed. Cátedra, 1994), pp. 32-34. En la elección de Hércules como auxiliar del estudioso dispuesto a perseverar en la virtud, pudo haber influído una glosa de Trevet (BNE, ms. 10193, f. 71r/v) relacionable com Séneca (De beneficiis, IV, vIII, 1-2), como sugiere Héctor Gonzàlvez Escolano, «Els models cavallerescos en el Curial e Güelfa», en J. Brumme et al. (eds.), Estudis de Llengua i Literatura Catalanes, 42. Miscel-lània Giuseppe Tavani, Barcelona, Publicacions de l'Abadia de Montserrat, 2001, vol. I, pp. 37-60; reed. en R. Friedlein y S. Neumeister (ed.), «Vestigia fabularum». La mitologia antiga a les literatures catalana i castellana entre l'edat mitjana i la modernitat, Barcelona, Curial-Publicacions de l'Abadia de Montserrat, 2004, pp. 31-48 (p. 47).

${ }^{42}$ Villena, Los doce trabajos, op. cit. (ed. Cátedra, 1994), p. 6.

${ }^{43}$ Jeremy N. H. Lawrance, «On Fifteenth-Century Spanish Vernacular Humanism», en I. D. Michael y R. Cardvell (eds.), Medieval and Renaissance Studies in Honour of Robert Brian Tate, Oxford, University of Oxford, 1985, pp. $63-79$ (p. 71). 
(Italia, ca. 1445-1448) que en Los treballs (Valencia, 1417), como es lógico- con el optimismo pedagógico del humanismo italiano, que animaba al individuo a convertirse, mediante el estudio de los clásicos, en un ser virtuoso y capaz de superar con éxito racional los infortunios de la vida ${ }^{44}$. El semidiós Hércules, icono representativo de ese esfuerzo individual, se convertirá por ello en el emblema de una nueva élite nobiliaria - la del Renacimiento- adornada por igual de arneses y de libros ${ }^{45}$.

\section{LA ENEIDA GLOSADA Y ALGUNAS «CONEXIONES» CON EL CURIAL}

El autor del Curial, como suele destacar la crítica literaria, traslada parte de la acción de su relato a Túnez con objeto de reeditar en cierto modo los amores de Dido y Eneas. Allí, el protagonista conoce a la joven estudiosa Camar, a quien expone el libro de Virgilio, «ben glossat e moralizat» ${ }^{46}$, ejerciendo de «maestre» o preceptor suyo (CeG III.43). Le explica aspectos difíciles de entender para quien no ha adquirido previamente un cierto nivel de profundización en los studia humanitatis. Curiosamente $-\mathrm{y}$ aunque no se nos den más detalles: ¿un guiño autobiográfico del autor?-, el caballero lombardo del siglo XIII «sabia molt bé tot lo Virgili e los altres libres» ${ }^{47} \mathrm{i}$ «li declarava [a Camar] moltes coses que ella no sabia ne entenia». El hecho de presentar un gran clásico traducido en «lengua materna» (árabe) podría incidir sobre la saludable idea -muy del Quattrocento- de la universalidad del acceso al saber, incluso para legos y caballeros científicos, desconocedores del latín. Complementariamente, el tema del preceptor y la doncella estudiosa enlaza con el ideal pedagógico que plasmó Leonardo Bruni en De studiis et litteris (1424), tratado dedicado a una culta mujer.

El autor de Curial e Güelfa, que -efectivamente- conoce bien la Eneida, sigue también aquí los pasos de Villena en la reivindicación literaria de la figura de Eneas, tan maltratada en la Edad Media, sobre

${ }^{44}$ Eugenio Garin, El Renacimiento italiano, Barcelona, Ariel, 1986, p. 67.

${ }^{45}$ Se nos está anunciado en el siglo xv, con esta búsqueda de referentes paganos y mitológicos, la consolidación de un nuevo tipo de nobleza de corte en Europa. Vid. Júlia Butinyà, «Les noves aristocràcia i noblesa a les acaballes de l'edat mitjana a través de la novel·la catalana Curial e Güelfa», Mirabilia, 9 (2009), pp. 292-312 (p. 294).

${ }^{46}$ Que la crítica suele relacionar con la versión de Villena. Vid. Isabel Grifoll, «Càmar i les clares dones», en R. Bellveser (coord.), Dones i literatura entre l'edat mitjana i el Renaixement, Valencia, Institució Alfons el Magnànim, 2012, vol. I, pp. 283-318 (pp. 292-294); Anònim, Curial e Güelfa, Lola Badia y Jaume Torró (eds.), Barcelona, Quaderns Crema, 2011, pp. 84-85 y 668 .

${ }^{47}$ Enyego d'Àvalos, embajador en Milán del rey de Aragón y más que probable autor del Curial, adquirió allí fama de ser un «loquentem Virgilianum», como lo califica su amigo el humanista Francesco Filelfo en el primero de sus Convivia Mediolanensia (Milán, 1443). Vid. Daniela Gionta, «Tra Filelfo e Pier Candido Decembrio», en M. Vegetti y P. Pissavino (eds.), I Decembrio e la tradizione della «Repubblica» di Platone tra Medioevo e Umanesimo, Nápoles, Bibliopolis, 2005, pp. 341-402. 
todo por causa de las Historias troyanas de Guido delle Colonne, basadas en los apócrifos Dictis y Dares. En la primera dedicatoria de su Eneida (Valencia, 1427), Villena ya adelantaba esta reivindicación: «iO poderoso Dios, que, pasados más de mill annos después de Eneas, susçitastes la virgiliana lengua faziéndole reparar las faltas que la Istoria de Frigius Dares testigua contra Eneas, así en caber en el vendimiento de su propia çibdat commo aver esfuerço remiso» ${ }^{48}$. Don Enrique comparte con el anónimo el interés por aleccionar, remitiendo a una epopeya latina que ejemplifica la caída y el restablecimiento de un héroe; aunque la «exégesis» a que somete don Enrique el mito sea todavía muy medieval ${ }^{49}$. Cuando el mismo autor, desavenido con Juan de Navarra, rededicó la obra a don Íñigo López de Mendoza, lo justificó porque tenía noticia de él y de «otros cavalleros del regno que deseavan de la leer ${ }^{50}$. Puede que entre dichos lectores expectantes se hallase ya nuestro anónimo ${ }^{51}$. Al menos, algunas intertextualidades permiten deducir que este tuvo a su alcance un ejemplar de la obra durante el proceso de documentación del Curial.

Ambos escritores coinciden en el uso de cultismos italianos como visivo/visiu ('con visión') ${ }^{52}$ o deificado/deïficat. Por ejemplo, Villena escribe que Hércules fue «entre los gentils deïficat» (proemio a Los dotze treballs $)^{53}$ y el anónimo, que Venus «per lo dit Júpiter fonch deïficada» ( $\mathrm{Ce} G$ III.17). Convendría disponer, lógicamente, de un trabajo sobre el léxico catalán y castellano de Villena contrastado con el del Curial, para poder cuantificar como conviene el alcance de la influencia del uno sobre el otro.

De momento, y sin poder profundizar en ello $^{54}$, pueden hallarse fácilmente recuerdos de lectura o notas tomadas de las glosas de Villena por parte del anónimo catalán cuando dotó de contenido mitológico el Curial. Verbigracia ${ }^{55}$ : la frase «su ídolo [el de Neptuno] se fazía una imagen asentada en un carro de cuatro ruedas e cuatro dalfines que la tiravan» (glosa 172 a la Eneida) encuentra reflejo en «Neptumno [...], en lo seu carro de quatre rodas, tirat per quatre dalfins» (CeG III.13), o en «Neptumpno, adonchs, muntat en lo seu

${ }^{48}$ Villena, Traducción y glosas, op. cit., vol. II, p. 25.

${ }^{49}$ Sol Miguel-Prendes, El espejo y el piélago. La «Eneida» castellana de Enrique de Villena, Kassel, Reichenberger, 1998, pp. 257 y 258, respectivamente.

${ }^{50}$ Santillana, Obras completas, op. cit., p. XXVII.

${ }^{51}$ Se puede deducir su presencia en la corte de Valencia por hápax y aspectos compartidos autores valencianos (Ausiàs Marc, Joanot Martorell, cartas de batalla...) y por indicios onomásticos. Vid. Abel Soler, «L'entorn valencià d'Enyego d'Àvalos i l'autoria de Curial e Güelfa», eHumanista/IVITRA, 11 (2017), pp. 401-430.

${ }_{52}$ Emili Casanova, «Los cultismos en Curial e Güelfa», en A. Ferrando (ed.), Estudis lingüistics, op. cit., vol. II, pp. 911-940 (p. 919).

${ }^{53}$ Cátedra, «Sobre la obra catalana», art. cit., 1988, pp. 137-138.

${ }^{54}$ Entre otras cosas, por no disponerse todavía de una edición del único ejemplar documentado -impreso- de Los dotze treballs: el del texto original en catalán, de 1417.

${ }^{55}$ Las cursivas de las distintas citas comparadas que vienen a continuación son nuestras. 
carro tirat per quatre dalfins» (CeG III.37) $)^{56}$. La glosa 147, donde Ganímedes es transformado erróneamente en hijo de un rey Yulo (sobrenombre virgiliano de Ascanio, hijo de Eneas), halla reflejo irónico en Curial e Güelfa, en cierto capítulo ( $C e G$ III.15) donde el autor teje una divertida parodia de desvaríos cometidos por mitógrafos medievales $^{57}$. Entre los parodiados se incluye el mismo Villena; con más razón, por tratarse de una lectura cercana, y seguramente compartida por autor y confidentes: «iE tu, Ganimedes, nat de Yulo, rey dels troyans, qui per lo dit Jovis en forma d'àguila fuist arrapat e muntat al cel, e fuist fet pincerna seu!». Enrique fue más conciso que su émulo: «Ganimedes.- Éste fue fijo del rey Yulo de Troya, muy fermoso mançebo del qual fingen los poethas que Júpiter, tomada forma de águyla, lo arrebató en sus uñas de la vall de Ida e se lo subió al çielo e lo fiço su pinçerna» ${ }^{58}$.

Del mismo modo, parece parodiarse con efecto hilarante una errata de Villena (cathacímbalas), cuando se habla de «dos labis, dues cathacimbales, als quals la lengua plega» ( $C e G$ III.0), simulando una mala lectura del «duo labia velut cymbala» de la fábula de Fulgencio, consultada en Pietro Alighieri ${ }^{59}$. Se trata de un curioso hápax compartido por ambos escritores. En Villena se lee: «e fazía tañer las cathacimbalas» $\mathrm{o}$ 《las cataçímbalas que sonaban.... ${ }^{60}$. El error parodiado en el Curial pudo deberse a la consulta por Villena de algún códice italiano que presentase una deficiente transcripción de cava cymbala (Catulo, Carmina, LXIII, 29) ${ }^{61}$. De hecho, el glosador de Virgilio alude -como el poema de Catulo- a Cibeles y al valle del Ida. Bien puede ser que algunos lectores/oyentes del Curial conociesen el verso de Catulo, y que pudiesen sonreír así ante la ocurrencia cómica del ingenioso escritor de la corte napolitana.

Otro hápax compartido que llama la atención es el de una diosa llamada Obstrea u Obsrea, que Villena «inventó» aglutinando los nombres de Ops ('Abundancia', diosa sabina, propiciadora de la fertilidad de los campos) y Rea (la gran madre minoica, a veces

${ }^{56}$ Villena, Traducción y glosas, op. cit., vol. II, p. 86. Coincidencia advertida por Badia y Torró (eds.), Curial e Güelfa, op. cit., p. 648.

${ }^{57}$ Los aparentes despropósitos que concentra este curioso capítulo hallan explicación en alguien que estuviese en contacto con los círculos humanísticos de Italia, como se demuestra en Soler, La cort napolitana, op. cit., vol. II, pp. 1512-1548, donde se trata de Las metamorfosis de Ovidio.

${ }^{58}$ Villena, Traducción y glosas, op. cit., vol. II, p. 74.

${ }^{59}$ Sobre este autor como fuente de erudición del anónimo, vid. Juan Francisco Mesa, «Pietro Aligheri, fuente de Curial e Güelfa», eHumanista/IVITRA, 1 (2012), pp. 185-196, y Soler, La cort napolitana, op. cit., vol. II, pp. 919-951.

${ }^{60}$ Villena, Traducción y glosas, op. cit., vol. II, pp. 69 y 197, respectivamente. No se trata, pues, de «une création savante de l'auteur» a partir del prefijo griego cata-, 'contra', como se propone en Anònim, Curial \& Guelfe, Jean-Marie Barberà (trad.), Toulouse, Anacharsis, 2007, p. 284, n. 91, sino un préstamo de Villena.

${ }^{61}$ Catul, Poesies, Joan Petit y Josep Vergés (ed. y trad.), Barcelona, Fundació Bernat Metge, 1928, p. 48. 
confundida con la romana Cibeles) ${ }^{62}$. En la glosa 480 se nos dice: «Çibelles, que por otro nombre fue llamada Opstrea ... ${ }^{63}$. En el texto de referencia constaría *Ops et Rea. Se suma a la coincidencia la extraña adaptación del latín al catalán de Caelum ('el Cielo', Urano), que en el Curial aparece como Cèlio ${ }^{64}$, y que también depende de Villena. Véase primero el texto catalán, obra de un lector de Luciano de Samósata ${ }^{65}$ : «Fingen, molt cara amiga, los poetes, que Cèlio fonch sens pare; e hach un fill apellat Saturno, e fonch rey de Cret, e forenli tallats los genitius, per ço com matava tots los fills que Cimbeles o Obsrea, sa muller, paria; los quals genitius foren lançats en les mars de Cipre, regne teu, e de la spuma de aquells nasqué Venus, filla tua» (CeG III.17). A continuación, la fuente parodiada (glosa 132): «E porque Celio otro non engendrase, Saturno cortóle los genityvos e lançólos en la mar, de cuya esperma Venus fue engendrada. E Saturno se casó con Obdrea, a quien los griegos llaman Çibelles» ${ }^{66}$. La repetición de antropónimos (Celio $>$ Cèlio) y de léxico (genityvos $>$ genitius) resulta esclarecedora. Como también lo es un -supuestolapsus calami: el sperma de la glosa se convierte en spuma en el $\mathrm{Cu}$ rial, una alteración pensada para contribuir al sinsentido cómico. Si se trata de un producto «de aquells», es decir, de los «genitius», no se entiende que se hable de spuma. Otro presunto lapsus mentis - ¿sátira premeditada?- transforma el hecho de que Celio «non engendrase» en un Cèlio que «fonch sens pare», detalle que complica todavía más la comprensión lógica y seria del texto catalán. Los detalles eruditos sobre el rey de Creta (tomado de la Grande e General Estoria) ${ }^{67}$ o sobre el reino de Chipre (muy conocido) son ya dos añadidos del anónimo, paródicos asimismo.

En el Curial, Dido, reina de Cartago, es incluida en una confusa genealogía («néta de Abanci, rey de Tir e de Sidònia, neboda d'Acrísio, rey dels argius, e filla de $B e l \cdot l o$, rey de molts regnes», $C e G$ III.66), que depende de la glosa 235 de Villena: «Dido, etc. Ésta fue dueña de muy grand proeza, fija del rey Bello, que señoreó $a$ Thiro e

${ }^{62}$ Como se advierte en Lola Badia y Jaume Torró, «Curial, entre Tristán y Orlando», en F. Bautista y J. Gamba (eds.), Estudios sobre la Edad Media, el Renacimiento y la temprana Modernidad, San Millán de la Cogolla, Sociedad de Estudios Medievales y RenacentistasInstituto Biblioteca Hispánica del Cilengua, 2010, pp. 43-60; Badia y Torró (eds.), Curial e Güelfa, op. cit., pp. 85 y 652.

${ }^{63}$ Villena, Traducción y glosas, op. cit., vol. II, p. 582.

${ }^{64}$ Gómez, «Curial e Güelfa, petges», art. cit., p. 60.

${ }^{65}$ Esta deuda, detectada ya por Ramon Aramon i Serra, «L'humorisme en el Curial e Güelfa», en Homenatge a Antoni Rubió i Lluch, Barcelona, 1936, vol. III, pp. 703-723 (pp. 719-720), resulta injustificable si no se presta atención, decididamente, al contexto italiano y al trasunto humanístico de la obra. Vid. Soler, La cort napolitana, op. cit., vol. II, pp. 1402 i ss.

${ }^{66}$ Villena, Traducción y glosas, op. cit., vol. II, p. 69.

${ }^{67}$ «E regnava otrossí estonces en la ysla de Creta el rey Celio, e Celio fue padre del rey Saturno» (I, 156a-b), apud Pilar Saquero y Tomás González Rolán, «Aproximación a la fuente latina del Libro de las generaciones de los dioses de los gentiles utilizada en la General Estoria de Alfonso X el Sabio», Cuadernos de Filología Clásica. Estudios latinos, 4 (1993), pp. 93-111 (pp. 97-98). 
a Sidonia. Este Bello fue hermano de Acrisio e fijo de $A b a n c ̧ i{ }^{68}$. Casi todas las fuentes clásicas explican que Agénor, rey de Tiro y Sidón, engendró a Belo o Matán I, rey de Tiro, y que este fue el padre de Dido. Sin embargo, el de Villena y el anónimo discrepan y mezclan los ancestros de Dido con los de Dánae. Lo que en el primer caso fue un error o confusión de lego, en el segundo -a nuestro criterio- se convierte en el Curial en una parodia cultista, por parte de alguien que ha estudiado durante años $-\mathrm{y}$ con un propósito más crítico que el del extravagante Villena- los mitos clásicos en fuentes óptimas o depuradas $^{69}$. Se entiende así que, en el controvertido capítulo de las concubinas de Júpiter ( $C e G$ III.15), se vuelva a parodiar de nuevo a Villena: en la confusión de Yulo, ya comentada, y en la cita de un «rey Alcedemonte», que es como Enrique llamaba al Alcídamas de Las metamorfosis ovidianas.

De interés es asimismo la coincidencia de Villena y el anónimo en la consideración de las Parcas como hadas: «Dijeron los poetas que tres fadas eran que fadaban a todos los omes.... $\rangle^{70}$. En Curial e Güel$f a$, cuando el protagonista acaba de salvar la vida de una dama llamada Cloto y empieza a sentirse atraído por Láquesis, recibe una carta de su alejada domina y exclama: «E [...] quals fades me fadaren...!» (CeG I.22). Más adelante, interpelado el caballero por las Musas, responde: «E quals fades me fadaren que yo tanta honor rebés...?» (CeG III.28). La expresión no es genuínamente catalana, sino castellana, y compartida, curiosamente, por Enrique de Villena, el poeta Álvarez de Villasandino -servidor del condestable Ruy López Dávalos- y el hasta ahora desconocido autor de Curial $^{71}$. La popularidad de dicha fórmula pudo deberse al conocido incipit del Romance de la Infantina: «Estas fadas me fadaron, / en haldas de una mi tía....» $\rangle^{72}$. En el Nàpoles de Alfonso V de Aragón, era frase conocida. Aparece

${ }^{68}$ Villena, Traducción y glosas, op. cit., vol. II, p. 127.

${ }^{69}$ De particular interés, en este sentido, es el testimonio de Valla sobre la implicación activa de su amigo y mecenas Enyego d'Àvalos («prelustrem... Egnigum Davalum»), probable autor del Curial, en tareas de debate humanístico y corrección crítica de textos clásicos. Cfr. Lorenzo Valla, Laurentii Valle Antidotum in Facium, Mariangela Regoliosi (ed.), Padua, Antenore, 1981, pp. 309-327 y 361-362.

${ }^{70}$ Villena, Traducción y glosas, op. cit., vol. II, p. 73, apud Rosa Navarro Durán, «Misterios de una extraña novela: Curial e Güelfa», Clarín. Revista de nueva literatura, 96 (2011), pp. 3-11 (p. 4). Vid. etiam Badia y Torró, «Curial e Güelfa», art. cit., p. 76.

${ }^{71} \mathrm{Si}$ se admite nuestra atribución del Curial al gran camarlengo D’Àvalos, hijo de dicho condestable (Soler, «Enyego d'Àvalos, autor...», art. cit.), que incluyó poemas de Villasandino en el Cancionero de Estúniza a, por él recopilado, se explicaría más facilmente su familiaridad con dicha frase.

${ }^{72}$ Vid. Jesús Suárez López, «Romance de la Infantina y el caballero burlado», Lletres asturianes, 31 (1989), pp. 121-132; Martín Sarmiento, Colección de voces y frases de la lengua gallega, ed. de J. L. Pensado, Salamanca, Universidad de Salamanca, 1970; Eladio Rodríguez González, Diccionario enciclopédico gallego-castellano, Vigo, Galaxia, 1958-1961, s. v. fadar. 
en Parténope la Fulgente de Diego del Castillo (vv. 93-94): «iOh, maldita sea la fada, / cuytada que me fadó! $\rangle^{73}$.

El conocimiento que el autor del Curial tenía de la obra de Villena se explica por una formación «ibérica», en la corte de Valencia, «prèvia a l'adquisició d'una informació més específicament italiana $\rangle^{74}$. Pero no es que, como suponen Lola Badía y Jaume Torró, ambos trabajasen «a partir de una misma Eneida glosada» ${ }^{75}$, sino que el autor del Curial tendría a su disposición, como es lógico, la Eneida de Villena.

\section{3. ¿UN «VIRGILIANISMO POLÍTICO» PARA EL NUEVO REX ITALICVS?}

Se ha caracterizado la lectura que Villena hizo de la Eneida como el punto de partida de un «virgilianismo político» que tomaría cuerpo con la historiografía renacentista, en exaltación de la Monarquía hispánica ${ }^{76}$. Don Enrique sostenía que Augusto encargó el poema épico a Virgilio para eternizar la gloria de «las gestas ymperiales» y «canonizar sus estrenuos fechos e perpetuar su indeleble memoria, dexándolos scriptos en el sçientífico e dulçe stillo virgiliano» ${ }^{77}$. Lara Vilà relaciona esta lectura de Virgilio con un intento de Enrique de Villena de asimilar al género historiográfico -según un criterio muy peculiar- la literatura épica, «embellecida mediante la retórica, para la conservación de las grandes hazañas $\rangle^{78}$. Esta idea pudo influir en la concepción de Curial e Güelfa como una especie de «crònica poetada $»^{79}$; como un anhelo -difícil de conseguir, eso sí- de «representar la cavalleria de mitjan segle XV amb les formes i recursos dels textos que havien donat glòria als cavallers romans, o millor dit, antics» ${ }^{80}$. Cabe añadir a esto un indisimulado trasfondo monárquico de la ficción caballeresca, así como el afán de conmemorar las gestas coetáneas del rey de Aragón: la conquista de Nápoles, 1435-1442; la concordia de Terracina con la Iglesia, 1443; la aspiración de la Corona de Aragón a ser «señora de Milán», 1446-1447... El propó-

${ }^{73}$ Lourdes Simó, «Parténope la fulgente, de Diego del Castillo, y el género de la elegía epistolar en la poesía cancioneril del siglo xv», Revista de poética medieval, 6 (2001), pp. 87-114 (p. 104).

${ }^{74}$ Badia y Torró (eds.), Curial e Güelfa, op. cit., p. 85. Profundizamos en esta formación valenciana, previa a la italiana, en A. Soler, «L'entorn valencià...», art. cit.

${ }^{75}$ Badia y Torró, «Curial, entre Tristán», art. cit., 2010 p. 58, n. 79. Se insiste en esta hipótesis explicativa en Idem (eds.), Curial e Güelfa, op. cit., p. 676, y en Idem, «Curial e Güelfa», art. cit., p. 91.

${ }^{76}$ Vid. Vilà, «Fama y verdad», art. cit.

${ }^{77}$ Villena, Traducción y glosas, op. cit., vol. II, p. 23.

${ }^{78}$ Vilà, «Fama y verdad», art. cit., p. 13.

79 Jaume Torró Torrent, «Sobre el Curial, Virgili i Petrarca», en A. Ferrando y A. Hauf (eds.), Miscel-lània Joan Fuster. Estudis de Llengua i Literatura Catalana, Barcelona, Publicacions de l'Abadia de Montserrat, 1991, vol. III, pp. 149-168. Lo sigue en este planteamiento Cingolani, «Finzione della realtà», art. cit., pp. 124-159.

${ }^{80}$ Jaume Torró, «Introducció» a Curial e Güelfa, J. Torró (ed.), Barcelona, Teide, 1993 (2 ${ }^{\mathrm{a}}$ ed. revisada y ampliada, 2002), pp. 7-40 (p. 32). 
sito epinicial, de hecho, condiciona diferentes aspectos de la novela: desde la antroponimia hasta el periplo del protagonista ${ }^{81}$.

Parece que ambos escritores de corte -un Enrique con estrechos vínculos valencianos y el otro, que pasó de Valencia a la corte napolitana- quisieron llenar el vacío que suponía la -tópica- falta de grandes «poetas» como los antiguos, pero excusándose por atreverse a ello en sus respectivos prólogos. Así, Villena (Los dotze treballs) ruega al lector que acepte «la present obra atenent les matèria e afectió mia, no havent esguard en la ruditat de la ordinació» ${ }^{82}$. Dichas palabras las recuerda el autor de Curial e Güelfa cuando se dispone a introducir «poètiques ficcions, scrites no en la manera que a la $m a-$ tèria se pertany, mas axí rudament e grossera» (CeG III.0). Aunque de distintas generaciones, los dos escritores «científicos»-caballeros ambos, si se admite nuestra atribución del Curial a D'Àvalos- participaron de un cierto espíritu de «elitismo cultural y nobiliario» y propugnaron «la educación de la clase regia y militar en unos textos particulares, entre los que la épica ocupa, indudablemente, un lugar privilegiado» ${ }^{83}$.

Si la Eneida de Villena fue presentada como speculum principis o «espejo doctivo» ${ }^{84}$ para un rey de Navarra regente en Valencia, no sería extraño pensar en el Curial como una ficción literaria con trasfondo de institutio principis o espejo formativo. Se celebraría así, poética y pedagógicamente, la refundación «virgiliana» de un Regnum Neapolitanum escindido de la Corona de Aragón, cuyo príncipe heredero, Ferran -un duque de Calabria adolescente todavía en la década del 1440-, llegó de Valencia a Italia en 1438. Sería interpretable Curial e Güelfa, pues, como un relato de divertida ficción, para el supuesto «plaer e consolació» de alguien importante y necesitado de pedagogía: ¿el príncipe bastardo de Nápoles? Con todo, puede que la dedicatoria -no se incluye en el borrador y único ejemplar conservado de la obra- fuese una simple excusa.

Quién sabe si la novela fue concebida inicialmente como un libro de «cavalleria moral», por retomar la terminología creada en catalán -y luego vertida al castellano- por Enrique de Villena. Él deseaba, puede que como el autor del Curial, que Los dotze treballs «faça fruit per imitació exemplar, i creiximent de virtuts i obstacle de vicis. I serà espill actual als gloriosos cavallers en armada milícia» ${ }^{85}$. Curial e Güelfa cumple a su manera con este propósito o cometido edificante, al tiempo que su autor se sirve del arte poética (retórica, alegoría,

${ }^{81}$ Antoni Ferrando, «Curial e Güelfa: una història amorosa en clau?», en R. Bellveser (coord.), Dones i literatura, op. cit., vol. II, pp. 797-830. Véase también el vol. III de Soler, $L a$ cort napolitana, op. cit.

${ }^{82}$ Riquer, Aproximació al «Tirant», op. cit., p. 277.

${ }^{83}$ Vilà, «Fama y verdad», art. cit., p. 21.

${ }^{84}$ Villena, Traducción y glosas, op. cit., vol. II, p. 26.

${ }^{85}$ Prólogo de la versión catalana original, de 1417, reproducido en Riquer, Aproximació al «Tirant», op. cit., p. 277 
mitología...) para embellecer con estilo y contenidos à la mode lo que, de entrada, pudiese parecer un libro de caballerías de la saga de los Tristanes. Como en el Hércules de Villena, en el Curial, «la verdad»-aquella «veritat» atribuida por Apolo a las Historias troyanas - «queda en un segundo plano, porque lo que importa realmente es ensalzar al sujeto», ya fuese un rey, un príncipe o un cortigiano humanista y paradigmático ${ }^{86}$.

El propósito principal de este docere delectando sería, eso sí, el de ofrecer al «symple leedor» cortesano alguos apuntes sutiles y útiles de «sçiençia» (política, metaliteratura, filosofía moral, simbología heráldica...) que el autor habría encriptado deliberadamente bajo un elaborado velamen literario. "Ansí, los dezires poéthicos fablan por tales encubiertas que, a los non entendidos, paresce oscuro e velado, e a los entendidos claro e manifiesto, segund fizo Virgilio» ${ }^{87}$. Ahora bien, a diferencia de Virgilio, Enrique de Villena y su discípulo más aventajado, don Enyego d'Àvalos (?), se expresaron en romance «común» y en un estilo no «intricado» en demasía; como intérpretes que pretendían ser del saber de los clásicos ante aquellos cortesanos expectantes, dispuestos a profundizar en él divertidamente. Se entiende así mucho mejor que Curial e Güelfa sea una obra repleta de picantes diálogos corteses; de facecias cultistas transparentes solo para unos pocos elegidos; de ironías metaliterarias y bromas con probable reflejo autobiográfico; de revelaciones onomásticas à clef y de «falses pistes» mitológicas, com las denomina Lola Badia ${ }^{88}$. El del anónimo es un libro que, como la Eneida romanceada que Curial ayudaba a entender a la dulce Camar, necesita ser glosado y declarado en algunos de sus secretos.

Recibido: 16/01/2017

Aceptado: 14/08/2017

${ }^{86}$ Vilà, «Fama y verdad», art. cit., p. 16.

${ }^{87}$ Villena, Traducción y glosas, op. cit., vol. II, pp. 49-50, glosa 50, apud Cátedra, «El sentido involucrado», art. cit., p. 151.

${ }^{88}$ Lola Badia, «De la "reverenda letradura" en el Curial e Güelfa», Caplletra, 2 (1987), pp. 5-18 (p. 8, n. 15). 


\section{$\cos$}

\section{ENRIQUE DE VILLENA Y CURIAL E GÜELFA}

RESUMEN: Enrique de Villena (1384-1434), noble aficionado a las letras, autor bilingüe en catalán y castellano, residente algunos años (ca. 14161429) de manera intermitente en la corte valenciana de Alfonso V de Aragón y Juan de Navarra, influyó en el concepto de literatura del autor de la novela caballeresca Curial e Güelfa (Enyego d'Àvalos?), escrita en catalán (Nápoles-Milán, c. 1445-1448) y relacionable con la corte italiana del Magnánimo. El Curial presenta conexiones intertextuales con la obra de Villena, además de hápax y neologismos compartidos. Su autor conoció, sin duda, Los dotze treballs d'Hèrcules (Valencia, 1417) y parodió errores mitográficos de la Eneida romanceada, glosada y moralizada por Villena (Valencia, 1427-1429), dos obras a las que alude implícitamente en la suya. Ambos escritores difundieron el ideal del vir scientificus Hércules (Coluccio Salutati) como alegoría del esfuerzo que los caballeros sçientificos/scientifichs ponían en estudiar los clásicos greco-latinos para crecer en virtud. Y ambos parece que anticiparon un «virgilianismo político» interpretable como la idea de embellecer literariamente los hechos históricos para eternizar la gloria militar en un digno formato.

Palabras Clave: Literatura catalana medieval, Enrique de Villena, Curial e Güelfa, Enyego d'Àvvalos, Eneida glosada.

\section{ENRIQUE DE VILLENA AND CURIAL E GÜELFA}

ABSTRACT: Enrique de Villena (1384-1434), a nobleman keen on arts, a bilingual author in Catalan and Spanish, who lived for some years (ca. 14161429) -in a sporadic way- in the Valencian court of Alfonso V of Aragon and John of Navarre, had an influence on the concept of literature to the author of the chivalric novel Curial e Güelfa (Enyego d'Àvalos?), written in Catalan (Naples-Milan, $c a$. 1445-1448) and which could be related with the Italian court of the Magnanimous. The Curial displays intertextual connections with Villena's work, apart from shared hapaxes and neologisms. The author was aware of -undoubtedly-Los dotze treballs d'Hèrcules (Valencia, 1417) and parodied mythographic mistakes from the romanced, glossed and moralised Aeneid by Villena (Valencia, 1427-1429), two works that he alludes to implicitly in his own. Both writers spread the ideal of the vir scientificus Hercules (Coluccio Salutati) as an allegory of the effort the sçientificos/scientifichs knights put on studying the Greek-Latin classics to grow up in virtue. And both seem to anticipate a «political virgilianism» which could be interpreted as the idea of embellishing literarily the historical events to perpetuate the military glory in a respectable format.

KeYwords: Medieval Catalan literature, Enrique de Villena, Curial e Güelfa, Enyego d'Àvalos, glossed Aeneid. 